\title{
BMJ Open Healthcare providers' gestational weight gain counselling practises and the influence of knowledge and attitudes: a cross-sectional mixed methods study
}

\author{
Jill Morris, ${ }^{1}$ Hara Nikolopoulos, ${ }^{1}$ Tanya Berry, ${ }^{2}$ Venu Jain, ${ }^{3}$ Michael Vallis, ${ }^{4}$ \\ Helena Piccinini-Vallis, ${ }^{5}$ Rhonda C Bell, ${ }^{1}$ on behalf of the ENRICH team
}

To cite: Morris J,

Nikolopoulos H, Berry T, et al. Healthcare providers' gestational weight gain counselling practises and the influence of knowledge and attitudes: a cross-sectional mixed methods study. BMJ Open 2017;7:e018527. doi:10.1136/ bmjopen-2017-018527

- Prepublication history and additional material for this paper are available online. To view these files, please visit the journal online (http://dx.doi org/10.1136/bmjopen-2017018527).

Received 5 July 2017 Revised 4 October 2017 Accepted 5 October 2017

\section{(a) CrossMark}

1Department of Agricultural Food and Nutritional Science, University of Alberta, Edmonton, Alberta, Canada

${ }^{2}$ Faculty of Physical Education and Recreation, University of Alberta, Edmonton, Alberta, Canada

${ }^{3}$ Department of Obstetrics and Gynecology, University of Alberta, Edmonton, Alberta,

Canada

${ }^{4}$ Department of Family Medicine, Behaviour Change Institute, Dalhousie University, Halifax, Nova Scotia, Canada ${ }^{5}$ Department of Family Medicine, Dalhousie University, Halifax, Nova Scotia, Canada

Correspondence to Professor Rhonda C Bell; rhonda.bell@ualberta.ca

\section{ABSTRACT}

Objective To understand current gestational weight gain (GWG) counselling practices of healthcare providers, and the relationships between practices, knowledge and attitudes.

Design Concurrent mixed methods with data integration: cross-sectional survey and semistructured interviews.

Participants Prenatal healthcare providers in Canada: general practitioners, obstetricians, midwives, nurse practitioners and registered nurses in primary care settings.

Results Typically, GWG information was provided early in pregnancy, but not discussed again unless there was a concern. Few routinely provided women with individualised GWG advice $(21 \%)$, rate of GWG $(16 \%)$ or discussed the risks of inappropriate GWG to mother and baby $(20 \%$ and $19 \%)$. More routinely discussed physical activity $(46 \%)$ and food requirements $(28 \%)$; midwives did these two activities more frequently than all other disciplines $(P<0.001)$. Midwives interviewed noted a focus on overall wellness instead of weight, and had longer appointment times which allowed them to provide more in-depth counselling. Regression results identified that the higher priority level that healthcare providers place on GWG, the more likely they were to report providing GWG advice and discussing risks of GWG outside recommendations $(\beta=0.71, P<0.001)$ and discussing physical activity and food requirements $(\beta=0.341, P<0.001)$. Interview data linked the priority level of GWG to length of appointments, financial compensation methods for healthcare providers and the midwifery versus medical model of care.

Conclusions Interventions for healthcare providers to enhance GWG counselling practices should consider the range of factors that influence the priority level healthcare providers place on GWG counselling.

\section{INTRODUCTION}

Supporting all women to achieve healthy gestational weight gain (GWG) is of clinical importance because GWG lower or higher than recommended is linked to a range of poor maternal, fetal and childhood outcomes. ${ }^{1}$ For mothers, excess GWG increases the risk of gestational diabetes

\section{Strengths and limitations of this study}

- This is a large and in-depth examination and comparison of healthcare providers' practices related to monitoring and discussing gestational weight gain (GWG) with pregnant women.

- This study is enhanced by the use of mixed methods. Mixed methods research is well suited for health services, which are complex and influenced by multiple factors.

- The findings from this study may have a wide applicability, as the topics covered in this survey are considered routine and are undertaken as part of standard prenatal care in most developed countries.

- It was not possible to calculate a true response rate for the survey because the survey was distributed using email lists and social media through professional associations and networks although these methods allowed for wider reach and more responses.

- Those who responded may be more likely to engage in activities related to GWG counselling which could lead to inflation of the reported frequency of specific GWG counselling practices. Nevertheless, the rates of some counselling practices reported in this study are quite low.

mellitus and hypertensive disorders in pregnancy, and this is of special concern if excessive GWG occurs early in pregnancy. ${ }^{2-4}$ Excess GWG also poses risks at delivery for the mother including increased likelihood of needing an instrumental delivery or a caesarean section, and surgical morbidity and mortality. ${ }^{13}$ Furthermore, these factors result in an increased risk for the fetus and neonate including the adverse consequences of macrosomia and shoulder dystocia, need for intensive care unit admission and the risk of perinatal death. ${ }^{135}$ In the long term, the child is at risk of an altered growth trajectory that may lead to obesity. ${ }^{6}$ Excess GWG also increases the risk of postpartum weight 
retention, which may leave a woman at an increased body mass index (BMI) to begin her next pregnancy. ${ }^{18}$ The cycle of excess GWG followed by postpartum weight retention and increasing maternal BMI can lead to increased risk in each subsequent pregnancy. ${ }^{9}$ These risks act synergistically resulting in a higher risk of metabolic and cardiovascular disease in later life for the mother as well as the child. ${ }^{10}$ Thus, excess GWG has short-term, long-term and intergenerational effects. ${ }^{11}$

To mitigate the risks of inappropriate GWG, many countries, including Canada, have released GWG guidelines. ${ }^{12}{ }^{13}$ Many of these are based on the Institute of Medicine (IOM) (USA) guidelines for GWG in pregnancy, which outline a range of total GWG over the course of pregnancy that is associated with optimal health outcomes for mother and child. ${ }^{14}$ In order for these guidelines to be of benefit to pregnant women, the IOM recommends that healthcare providers advise women on the recommended range of GWG based on prepregnancy BMI, and that they track and discuss weight progress over the course of pregnancy, as well as offering tailored counselling on dietary intake and physical activity. ${ }^{15}$ Many countries provide guidance to healthcare providers in the form of evidence-based guidelines in order to support them in providing physical activity and nutrition counselling to pregnant women. ${ }^{16-19}$

There is growing evidence to suggest that the quality of GWG counselling interactions needs improvement, as women and healthcare providers report conflicting views of these interactions. ${ }^{20}$ Many women report that their healthcare provider did not provide recommendations for GWG during their prenatal care, nor provide counselling about nutrition and physical activity behaviours during pregnancy ${ }^{2122}$ Healthcare providers have reported taking a reactive approach, initiating a discussion about weight in pregnancy only after weight exceeds the recommendations. ${ }^{23}{ }^{24}$ Healthcare providers may lack knowledge or skills to undertake this type of counselling, ${ }^{25} 26$ or consider GWG to be a low priority in the context of a typical prenatal visit. ${ }^{23}$

Women may see a variety of healthcare provider disciplines for prenatal care including general practitioners, obstetricians, midwives, nurse practitioners and registered nurses. ${ }^{27}$ There is some evidence to suggest that the approach to GWG counselling may vary by healthcare provider discipline ${ }^{28} 29$; however, this area has not been fully explored. In order to better support healthcare providers to have positive GWG counselling interactions with women, there needs to be a detailed understanding of current practices, and what is influencing these practices. This information can be used to develop interventions to promote appropriate GWG in routine prenatal care. As such, the objectives of this study were to characterise and compare the GWG counselling practices of healthcare providers who provide prenatal care; and to examine potential influences on advice and counselling practices.

\section{METHODS}

\section{Study design}

This study was conducted using a concurrent mixed methods design, consisting of an online survey and semistructured qualitative interviews. Qualitative and quantitative data were collected in tandem, analysed separately and integrated. ${ }^{30}$ Mixed methods research is well suited for research questions that call for real-life contextual understandings and multilevel influences, and lends itself well to the development of complex interventions. ${ }^{31}$

Ethics approval for this study was obtained from the Health Research Ethics Board at the University of Alberta (Study identification Pro00045899). All participants provided informed consent to participate in this study.

\section{Quantitative methods}

\section{Survey development}

A survey questionnaire was developed, pilot-tested and assessed for content validity by a team of researchers with expertise in the areas of obstetrics, nutrition, exercise physiology, health promotion and health psychology (online supplementary file).

\section{Recruitment and data collection}

Healthcare providers including general practitioners, obstetricians, midwives, nurse practitioners and registered nurses in primary care settings from across Canada were recruited through professional associations and networks who agreed to distribute survey information to their members. All healthcare providers who provided prenatal care were eligible to participate. The survey was available from December 2014 to May 2015 on Research Electronic Data Capture software hosted at the University of Alberta. ${ }^{32}$

\section{Outcomes}

Survey participants provided information about their professional characteristics, and were asked to respond to questions regarding their practices, knowledge and attitudes related to GWG, nutrition and physical activity. Specifically, participants were asked about the proportion of their pregnant patients with whom they undertook selected GWG counselling practices as outlined in the IOM recommendations, ${ }^{15}$ using a scale from $1(<10 \%$ of pregnant patients) to 5 ( $>90 \%$ of pregnant patients). Respondents were also asked for their self-assessment of their general knowledge to support GWG counselling, their detailed knowledge of the content of practice guidelines related to GWG (specifically the IOM/ Health Canada GWG guidelines, ${ }^{33}$ and Health Canada's nutrition guidelines ${ }^{34}$ and physical activity guidelines ${ }^{35}$ ) and the priority level they placed on discussing, assessing and assisting women with GWG (eg, Given all the issues of concern during a typical prenatal visit, I consider discussing GWG a high priority). Responses indicated level of agreement with each statement on a scale from 1 (strongly disagree) to 5 (strongly agree). The survey also examined whether healthcare providers considered 
themselves to be the most appropriate person within their practice setting to provide GWG counselling ( $I$ am the most appropriate provider in my practice setting to discuss $G W G)$.

\section{Data analysis}

GWG counselling practices of each healthcare provider group were calculated as frequency and percentage of responses, dichotomised into 'Routine (undertaken with $>90 \%$ of pregnant patients)' and 'Not routine' (all other response choices) based on the IOM recommendations that these practices occur with every woman (IOM, 2013). ${ }^{15}$ Cases with missing data were removed from analyses. Principal components analysis was used to reduce the numerous survey questions into a smaller number of factors. The mean score of the items loading onto each factor was used to represent that factor score for respondents. ${ }^{36}$ For example, four questions loaded onto a factor that was named 'providing weight gain advice and discussing risks' and were averaged together into a composite score for that factor. Mean scores were calculated for the remaining factors of general knowledge, detailed knowledge of practice guidelines and the priority level healthcare providers place on GWG, in a similar manner. Differences in mean composite scores were compared among healthcare provider disciplines using one-way analysis of variance (ANOVA) with Bonferroni post hoc tests; residuals for all composite scores were normally distributed. Mean scores for each factor were used in multiple linear regression models to evaluate the relationship between the predictors of interest and GWG counselling practices. For all models, multicollinearity was not an issue with all tolerance values $>0.36$ and variance inflation factors $<2.8$.

\section{Qualitative methods \\ Materials}

A semistructured interview guide was developed by the study team based on the study objectives and included questions and prompts regarding healthcare provider practices in relation to GWG, as well as the reasons behind these practices. The interview guide also included questions regarding provider knowledge in and attitudes towards GWG.

\section{Recruitment and data collection}

Potential participants were identified through collaborating members of the study team. A purposive sample of maximum variation was recruited to gather the perspectives of healthcare providers from the different disciplines practising in urban or rural locations in two Canadian provinces (Alberta and British Columbia). When these contacts were exhausted, an advertisement was distributed by email to medical clinics relevant to the requirements for variability in the sample. Interviews were conducted over the telephone, audio-recorded and transcribed verbatim.

\section{Data analysis}

Qualitative content analysis was used to describe and inductively interpret the data. ${ }^{38}$ Qualitative content analysis is a process that is a 'reduction and sense making effort that takes a volume of qualitative material and attempts to identify core consistencies and meanings' (Patton, p45). ${ }^{39}$ Audio recordings and transcripts were reviewed, and reviewed again while making notes about key words and phrases. Key concepts were categorised and recategorised as patterns emerged. Data analysis occurred concurrently with data collection, and sampling adequacy was demonstrated by saturation of the data, as replication occurred in categories as new participants were included in the analysis. ${ }^{40}$ Findings were discussed and approved by the study team.

\section{Data integration}

The categories emerging inductively from the interviews were compared with the results from the quantitative survey to determine if findings from each method confirmed the other, as well as to expand the strength of each type of data to better explain the phenomenon. ${ }^{41}$

\section{RESULTS}

\section{Participant characteristics}

Overall, 1189 healthcare providers responded to the survey. Of these, $122 \mathrm{did}$ not meet the eligibility criteria (ie, did not see pregnant women in their practice), 27 did not specify their healthcare provider discipline, 155 did not answer any questions beyond practice characteristics and 377 indicated a healthcare provider discipline that was outside the scope of these analyses. Thus, 508 responses from general practitioners, obstetricians, midwives, nurse practitioners and registered nurses in primary care settings from across Canada are included in this analysis (table 1). Twenty-three healthcare providers from these same disciplines participated in the interviews.

\section{GWG counselling practices of healthcare providers Providing weight gain advice and discussing risks}

A small proportion of healthcare providers routinely provided women with a GWG target based on their prepregnancy BMI and discussed the recommended rate of GWG based on their GWG target (21\% and 16\%; table 2). Few indicated that they routinely discussed the impacts of inappropriate GWG on mother (20\%) and baby $(19 \%)$. The composite score for providing weight gain advice and discussing the risks did not differ between healthcare provider disciplines (table 3).

Key concepts and quotes relating to counselling practices that emerged from the interviews are outlined in table 4. Interviewees described the first prenatal visit as including measurement of weight, calculation of BMI and a large amount of information sharing, including general information on GWG. Some healthcare providers advised women on a total GWG target; however, this was not always congruent with guidelines. The amount of 
Table 1 Characteristics of participating Canadian healthcare providers

\begin{tabular}{|c|c|c|c|c|}
\hline & \multicolumn{2}{|c|}{$\begin{array}{l}\text { Survey } \\
\text { participants, } \\
\mathrm{n}=508\end{array}$} & \multicolumn{2}{|c|}{$\begin{array}{l}\text { Interview } \\
\text { participants, } \\
\mathrm{n}=23\end{array}$} \\
\hline & $\mathbf{n}$ & $\%$ & $\mathbf{n}$ & $\%$ \\
\hline \multicolumn{5}{|l|}{ Healthcare provider discipline } \\
\hline General practitioner & 159 & 31 & 7 & 30 \\
\hline Obstetrician & 139 & 27 & 5 & 22 \\
\hline Midwife & 97 & 19 & 5 & 22 \\
\hline Registered nurse-primary care & 75 & 15 & 4 & 17 \\
\hline Nurse practitioner & 38 & 7 & 2 & 9 \\
\hline \multicolumn{5}{|l|}{ Province } \\
\hline British Columbia & 55 & 11 & 9 & 39 \\
\hline Alberta & 149 & 30 & 14 & 61 \\
\hline Saskatchewan and Manitoba & 56 & 11 & NA & \\
\hline Ontario & 168 & 33 & & \\
\hline Quebec & 17 & 3 & & \\
\hline Maritimes $^{*}$ & 47 & 9 & & \\
\hline Territories $†$ & 11 & 2 & & \\
\hline \multicolumn{5}{|l|}{ Location of practice } \\
\hline Urban & 296 & 58 & $\mathrm{NC}$ & \\
\hline Rural & 125 & 25 & & \\
\hline Urban and rural & 86 & 17 & & \\
\hline \multicolumn{5}{|c|}{ Proportion of all patients who are pregnant women (\%) } \\
\hline$<10$ & 103 & 20 & NC & \\
\hline $10-30$ & 94 & 19 & & \\
\hline $30-60$ & 119 & 23 & & \\
\hline $60-90$ & 46 & 9 & & \\
\hline$>90$ & 146 & 29 & & \\
\hline \multicolumn{5}{|l|}{ Stage of pregnancy at first visit } \\
\hline Before pregnancy & 30 & 6 & $\mathrm{NC}$ & \\
\hline First trimester & 328 & 65 & & \\
\hline Second trimester & 74 & 15 & & \\
\hline Third trimester & 34 & 7 & & \\
\hline Don’t know/too variable to say & 41 & 8 & & \\
\hline
\end{tabular}

*Maritimes=Newfoundland and Labrador, New Brunswick, Nova Scotia.

†Territories=Northwest Territories, Yukon Territory (no respondents from Nunavut).

NA, not applicable; NC, not captured.

information provided in the first visit was perceived by the healthcare providers to be overwhelming for women.

\section{Weight assessment}

Approximately three-quarters of respondents weighed women at every visit $(76 \%)$, while half of respondents would routinely relay GWG information to women every time they are weighed (table 2). Midwives reported measuring weight at every visit less frequently than all other disciplines (table 3).
Interviewees noted that weight was typically measured at each visit, except for midwives who generally measured women's weight if clinically necessary, or if women requested them to do so (table 4). After the first visit, interview participants indicated that they revisited the topic to varying levels of depth, typically only when the healthcare provider or woman expressed concern about her weight.

Discussing physical activity and food requirements

Nearly half $(46 \%)$ of healthcare providers reported routinely discussing physical activity with women while about one-third routinely discussed appropriate extra food requirements (28\%), and only about one-third felt they could routinely give examples of appropriate changes that women could make to meet extra food requirements $(32 \%$ ) (table 2). In contrast, over two-thirds would discuss the importance of prenatal vitamins $(67 \%)$. The composite score for the three survey questions regarding discussing physical activity and food requirements differed between healthcare provider disciplines (table 3). Midwives did this more frequently than all other disciplines except for nurse practitioners.

Healthcare providers of all disciplines described providing general information on GWG, physical activity and nutrition in the early stages of pregnancy, and many indicated providing women with printed resources in this area (table 4). The midwives interviewed described spending more time assessing women's current lifestyle and providing individualised advice than did physicians (table 4).

\section{Predictors of counselling practices}

Healthcare providers, regardless of discipline, reported similar responses for having appropriate general knowledge of GWG, physical activity and nutrition, as well as knowledge of related practice guidelines (table 3); only the difference between midwives and registered nurses responses was significant. There were significant differences in the level of priority placed on GWG. Midwives and obstetricians had lower composite scores for the priority level they place on GWG than general practitioners and nurse practitioners, but did not differ significantly from each other (table 3). The majority of healthcare providers considered discussing GWG with women to be within their role $(77 \%)$.

Predictors of providing weight gain advice and discussing risks

The composite score for providing weight gain advice and discussing risks of inappropriate GWG was most strongly related to the priority level that healthcare providers placed on GWG (table 5), followed by their detailed knowledge of GWG, physical activity and nutrition guidelines.

Generally, healthcare providers in the interviews reported that GWG discussions may receive lower priority due to the time constraints in a typical appointment (table 4). This was related to their compensation 
Table 2 Survey responses regarding gestational weight gain counselling practices routinely undertaken (with $>90 \%$ of pregnant patients) by Canadian healthcare providers

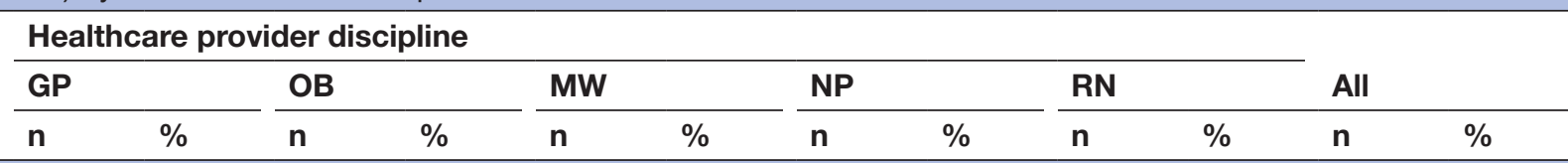

I provide women with a weight gain target based on their prepregnancy BMI

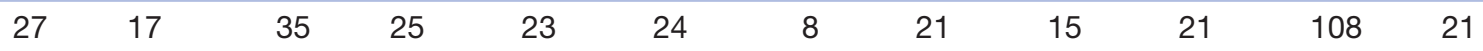

$\begin{array}{lll}\text { Missing } & 1\end{array}$

I discuss the recommended rate of weight gain based on their weight gain target

\begin{tabular}{|c|c|c|c|c|c|c|c|c|c|c|c|c|}
\hline & 22 & 14 & 19 & 14 & 15 & 16 & 11 & 29 & 15 & 21 & 82 & 16 \\
\hline Missing & & & & & & & & & & & 6 & 1 \\
\hline \multicolumn{13}{|c|}{ I discuss the impact of inappropriate weight gain on the mother during pregnancy } \\
\hline & 22 & 14 & 33 & 24 & 21 & 22 & 13 & 34 & 11 & 15 & 100 & 20 \\
\hline Missing & & & & & & & & & & & 4 & 1 \\
\hline
\end{tabular}

I discuss the impact of inappropriate weight gain on the baby

\begin{tabular}{|c|c|c|c|c|c|c|c|c|c|c|c|c|}
\hline & 21 & 13 & 30 & 22 & 21 & 22 & 15 & 40 & 10 & 14 & 97 & 19 \\
\hline Missing & & & & & & & & & & & 7 & 1 \\
\hline \multicolumn{13}{|c|}{ I weigh women at every visit } \\
\hline Missing & & & & & & & & & & & 4 & 1 \\
\hline \multicolumn{13}{|c|}{ I relay weight gain information to women every time I weigh them } \\
\hline Missing & & & & & & & & & & & 7 & 1 \\
\hline \multicolumn{13}{|c|}{ I discuss appropriate physical activity with pregnant women } \\
\hline & 75 & 48 & 53 & 38 & 61 & 64 & 20 & 53 & 22 & 31 & 231 & 46 \\
\hline Missing & & & & & & & & & & & 7 & 1 \\
\hline \multicolumn{13}{|c|}{ I discuss appropriate extra food requirements with pregnant women } \\
\hline \multicolumn{13}{|c|}{ I can easily give examples of appropriate changes that women could make to meet extra food requirements } \\
\hline & 40 & 26 & 30 & 22 & 48 & 50 & 17 & 46 & 23 & 32 & 158 & 32 \\
\hline Missing & & & & & & & & & & & 9 & 2 \\
\hline \multicolumn{13}{|c|}{ I discuss the importance of taking prenatal vitamins } \\
\hline & 124 & 79 & 85 & 61 & 49 & 51 & 34 & 90 & 44 & 61 & 336 & 67 \\
\hline Missing & & & & & & & & & & & 6 & 1 \\
\hline
\end{tabular}

BMI, body mass index; GP, general practitioner; MW, midwife; NP, nurse practitioner; OB, obstetrician; RN, primary care registered nurse.

method, as general practitioners and obstetricians were remunerated in a fee-for-service model that resulted in restriction on the length of appointments, as well as the topics covered. Midwives were compensated by course-of-care, which resulted in longer and more flexible appointments. However, midwives described a lower priority level placed on GWG, as their practice was less focused on weight, in particular weight assessment, and more focused on a woman's overall health and well-being. Healthcare providers' perceptions of the sensitivity of discussing GWG with pregnant women were also related to their providing weight gain advice and discussing risks (table 4). Some healthcare providers noted their discomfort with initiating GWG discussions, or discussing GWG too frequently, as they were concerned that this may cause psychological distress for the woman.

Predictors of discussing physical activity and food requirements The priority level that healthcare providers place on GWG, their detailed knowledge of GWG, nutrition, and physical activity guidelines, and their general knowledge of this area were all significantly related to their discussing physical activity and food requirements with women during a prenatal visit (table 6). After adjustment for practice characteristics, being a midwife remained a significant predictor of this activity within a prenatal visit. 
Midwifery practices in relation to discussing physical activity and food requirements also emerged from the interview data (table 4). Midwives reported that their approach focused on overall health and wellness, and centred on support for women. Knowledge was another key factor that came to light in the interviews, as some healthcare providers noted a need for additional knowledge, particularly in nutrition and maternal obesity. For healthcare providers working within a multidisciplinary team, access to dietetic services was an important enhancement to GWG counselling practices.

\section{DISCUSSION}

GWG counselling by healthcare providers falls below the recommendations from the IOM and other national health agencies. ${ }^{15}$ Although many of the healthcare providers interviewed indicated that they regularly calculate and record women's prepregnancy BMI, few survey respondents from any discipline routinely provided women with a comprehensive GWG recommendation and advice on their rate of GWG based on their prepregnancy BMI. In addition, few survey respondents reported discussing the risks of inappropriate GWG with women. While many healthcare providers reported providing a general message of the importance of prenatal vitamins, fewer reported routinely discussing topics such as appropriate extra food requirements. Weight was typically measured at each prenatal appointment, but not discussed unless it was a concern. This is in contrast with what women report they need from their healthcare provider, as other studies from our research group have indicated that women would like their healthcare provider to initiate a discussion about GWG early in pregnancy, and continue the discussions throughout pregnancy and postpartum so that they are updated on their GWG progress. ${ }^{22}$

The low rates of some of these counselling practices are concerning since it is likely that survey respondents are those who would be most likely to counsel women about GWG. There is evidence suggesting that women whose healthcare providers discuss GWG and related lifestyle behaviours in pregnancy with them have lower GWG and lower likelihood of having a baby that is large for gestational age. ${ }^{42-44}$ This underlines the potential level of influence that healthcare providers have with pregnant women and the importance of refining their training or antenatal care pathways to support such conversations.

To our knowledge, this is the first mixed methods study to examine GWG counselling, in particular for the specific counselling practices recommended by IOM.

While survey and qualitative research studies from various parts of the world have also found low rates of GWG counselling as reported by patients, other surveys of healthcare providers have found high self-reported rates of counselling. ${ }^{20}{ }^{28}$ This discrepancy may be due to the frequency with which healthcare providers undertake counselling, as studies from the US have found that they report discussing GWG more often with women who are overweight or obese at the start of their pregnancy. ${ }^{24}$ 


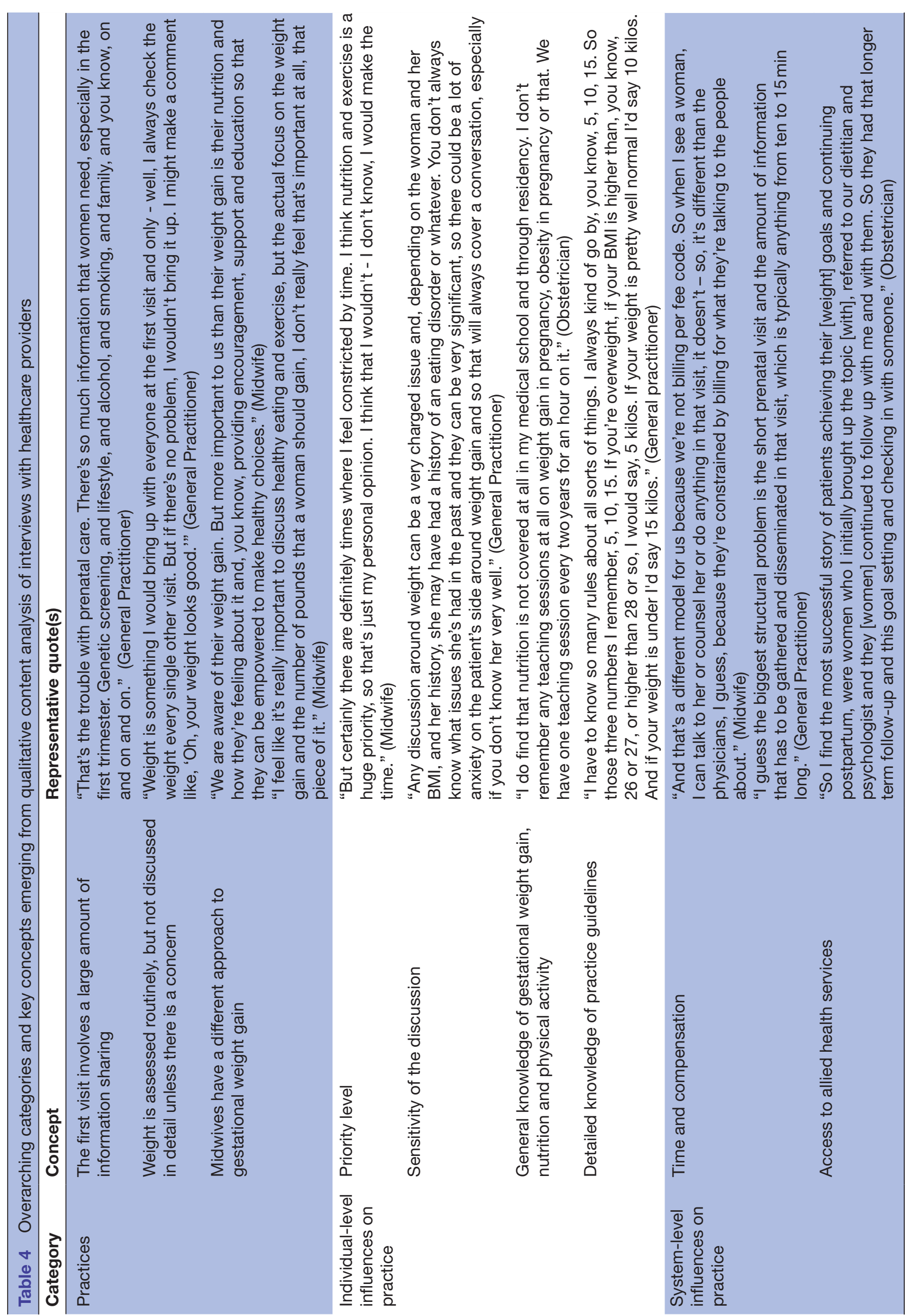


Table 5 Predictors of Canadian healthcare providers providing advice to pregnant women about gestational weight gain (GWG) and discussing risks of inappropriate weight gain during a prenatal visit

\begin{tabular}{|c|c|c|c|}
\hline \multirow[b]{2}{*}{ Variable } & \multicolumn{3}{|l|}{ Model† } \\
\hline & Unstd $\beta$ & SE of $\beta$ & Std $\beta$ \\
\hline Constant & $-1.14^{\star \star}$ & 0.38 & \\
\hline \multicolumn{4}{|l|}{ General practitioner (reference) } \\
\hline Obstetrician & 0.242 & 0.145 & 0.093 \\
\hline Midwife & -0.076 & 0.199 & -0.026 \\
\hline Primary care RN & -0.029 & 0.177 & -0.008 \\
\hline Nurse practitioner & -0.057 & 0.206 & -0.012 \\
\hline Detailed knowledge of GWG, physical activity and nutrition guidelines & $0.26^{\star \star}$ & 0.069 & 0.202 \\
\hline General knowledge in GWG, physical activity and nutrition & 0.098 & 0.081 & 0.065 \\
\hline Priority level of discussing, assessing and assisting women with appropriate weight gain & $0.71^{\star \star}$ & 0.071 & 0.459 \\
\hline Role (I am the most appropriate provider to discuss gestational weight gain) & 0.172 & 0.133 & 0.056 \\
\hline$R^{2}$ & 0.392 & & \\
\hline
\end{tabular}

${ }^{* *} \mathrm{P}<0.01$.

†Model is adjusted for: urban/rural location, proportion of all patients who are pregnant and trimester of pregnancy at first visit.

GWG, gestational weight gain; RN, registered nurse; Std, sandardised; Unstd, unstandardised.

Therefore, they may report that they provide GWG counselling, but not to every pregnant woman. Further, when the depth of this counselling is explored, the self-reported rates are likely to diminish. Future studies should objectively assess the quality of these discussions and evaluate their impact on GWG, health behaviours like physical activity and diet and women's perceptions of support. Furthermore, research is needed to elucidate the most effective counselling methods that will help women achieve appropriate GWG. This additional information could help guide or refine approaches to antenatal care undertaken by different groups of care providers.
This study identified multilevel influences on GWG counselling. Most notably, the priority level that healthcare providers placed on GWG had the strongest relationship with their practices. The qualitative results provided context to this finding, linking the priority level of GWG to factors at the healthcare system level, such as the time available in a typical prenatal appointment, and the compensation that healthcare providers receive for their time. Additionally, this study identified factors at the individual level. This included the importance of detailed knowledge of practice guidelines, which also was strongly associated with counselling practices.

Table 6 Predictors of Canadian healthcare providers discussing physical activity and food requirements with women as part of a prenatal visit

\begin{tabular}{|c|c|c|c|}
\hline \multirow[b]{2}{*}{ Variable } & \multicolumn{3}{|l|}{ Model† } \\
\hline & Unstd $\beta$ & SE of $\beta$ & Std $\beta$ \\
\hline Constant & 0.688 & 0.345 & \\
\hline Obstetrician & 0.022 & 0.13 & 0.009 \\
\hline Midwife & $0.518^{\star \star}$ & 0.179 & 0.192 \\
\hline Nurse practitioner & 0.342 & 0.189 & 0.077 \\
\hline Detailed knowledge of GWG, physical activity and nutrition guidelines & $0.277^{\star \star}$ & 0.063 & 0.229 \\
\hline General knowledge in GWG, physical activity and nutrition & $0.311^{\star \star}$ & 0.073 & 0.22 \\
\hline Priority level of discussing, assessing and assisting women with appropriate weight gain & $0.341^{\star *}$ & 0.064 & 0.236 \\
\hline Role (I am the most appropriate provider to discuss gestational weight gain) & 0.18 & 0.12 & 0.063 \\
\hline
\end{tabular}

${ }^{* *} \mathrm{P}<0.01$.

†Model is adjusted for: urban/rural location, proportion of all patients who are pregnant and trimester of pregnancy at first visit. GWG, gestational weight gain; RN, registered nurse; Std, standardised; Unstd, unstandardised. 
One novel finding was the new insights into the different approach reported by midwives. Midwives noted that their focus on the overall well-being of the women meant they discussed physical activity and nutrition in more depth than did physicians, and they measured weight less frequently. Even after controlling for multiple other predictors, midwives were significantly more likely than other healthcare providers to report discussing physical activity and food requirements with women during routine prenatal care. In other research, patients of midwives were more likely to recall having discussed physical activity with their healthcare provider as compared with patients of general practitioners and obstetricians, ${ }^{29}$ and midwives themselves report providing physical activity counselling to women more frequently than other disciplines. ${ }^{20}{ }^{28}$ While the present study considered physical activity and nutrition counselling practices as one composite score, there seems to be growing evidence that midwives provide more lifestyle counselling than other healthcare provider disciplines. The impact of counselling by a midwife as compared with other disciplines on the health outcomes for women is an area for future exploration.

\section{Strengths and limitations}

A major strength of this study is the use of mixed research methods. This allowed for some verification of findings between methods, and provided a broader picture of "who is doing what', as well as 'why and how are they doing it'. To our knowledge, this is the largest and most comprehensive survey on this topic to date. While prenatal care varies between countries, the topics covered in this survey are considered routine and are undertaken as part of standard prenatal care in most developed countries.

This study has limitations that should be considered. It was not possible to calculate a true response rate for the survey since the survey was distributed using email lists and social media through professional associations and networks. While this method of recruitment allowed for a wider reach, and ultimately more responses, those who responded may be more likely to engage in activities related to GWG counselling. This could lead to inflation of the reported frequency of specific GWG counselling practices. This is concerning as they are already quite low for some counselling practices and further highlights the need for targeted interventions in this area.

The qualitative interviews were only conducted in two provinces, and there is the potential that this does not accurately capture the practices and predictors in other geographic areas. However, the congruency of the qualitative and quantitative findings suggests that this is unlikely. Furthermore, a recent systematic review found few differences in barriers and facilitators to pregnancy weight management in studies from around the world, suggesting that the findings of the current study may help inform practice in various healthcare systems. ${ }^{45}$

\section{Recommendations}

Interventions to implement the best practices should consider the multilevel influences on GWG counselling practices, as well as the discipline of the healthcare provider, in order to be effective at changing healthcare provider behaviours. Providers across disciplines require knowledge of GWG, physical activity and nutrition guidelines and some may need system-level changes such as more time in an appointment to help them make it a priority in their practice. A different model for dissemination of this knowledge needs consideration. Multidisciplinary clinics that include professionals with a background in nutrition and physical activity, and group educational sessions may be important in this regard. ${ }^{46}$ The latter approach could allow participants to discuss these issues among themselves and may provide positive reinforcement of new knowledge and help to shift old beliefs. ${ }^{42}$ Furthermore, discussion of healthy GWG and maintenance of a healthy weight trajectory with women by health providers is a missed opportunity for positive feedback for a healthy and potentially long-term behaviour.

Expanding discussions on GWG to a healthier lifestyle is highly relevant given the growing body of evidence related to its impact on disease in later life. ${ }^{10}$ Healthcare providers are well positioned to help women identify plans to change behaviour and improve health outcomes. Strong communication between healthcare providers and pregnant women is a key component to moving forward. Supporting healthcare providers to better counsel their pregnant patients on appropriate GWG is one important step towards breaking the intergenerational cycle of obesity, and improving the health of generations to come.

Acknowledgements We would like to thank all of the participants in both components of the study for their time and insight. We would also like to thank Melisa Spaling for her contribution to the analysis of the qualitative data and Adam King for his help with recruiting participants to interview from British Columbia.

Contributors RCB and HN designed the study, and with MV and HP-V developed the interview guide and survey questionnaire. JM and HN recruited interview participants and conducted the interviews. JM recruited survey participants, conducted the qualitative and quantitative analyses and wrote the first draft of the manuscript. HN and RB contributed to the qualitative analysis and TB and RCB contributed to quantitative analysis. VJ contributed to recruitment of interview participants. All authors made significant contributions to the critical review and revisions of the manuscript. JM and RCB are the guarantors of the manuscript. All authors had full access to all of the data (including statistical reports and tables) in the study and can take responsibility for the integrity of the data and the accuracy of the data analysis. JM affirms that the manuscript is an honest, accurate and transparent account of the study being reported; that no important aspects of the study have been omitted.

Funding This study was funded by grants from Alberta Innovates- Health Solutions and the Danone Institute of Canada. The funders had no involvement in the study design; in the collection, analysis, and interpretation of data; in the writing of the report; nor the decision to submit the article for publication.

Competing interests None declared.

Ethics approval Health Research Ethics Board at the University of Alberta.

Provenance and peer review Not commissioned; externally peer reviewed.

Data sharing statement Data used in this study are not currently available for data sharing.

Open Access This is an Open Access article distributed in accordance with the Creative Commons Attribution Non Commercial (CC BY-NC 4.0) license, which 
permits others to distribute, remix, adapt, build upon this work non-commercially, and license their derivative works on different terms, provided the original work is properly cited and the use is non-commercial. See: http://creativecommons.org/ licenses/by-nc/4.0/

(C) Article author(s) (or their employer(s) unless otherwise stated in the text of the article) 2017. All rights reserved. No commercial use is permitted unless otherwise expressly granted.

\section{REFERENCES}

1 Viswanathan M, Siega-Riz AM, Moos MK, et al. Outcomes of maternal weight gain. Evid Rep Technol Assess 2008;168:1-223.

2. Carreno CA, Clifton RG, Hauth JC, et al. Excessive early gestational weight gain and risk of gestational diabetes mellitus in nulliparous women. Obstet Gynecol 2012;119:1227-33.

3. Joy S, Istwan N, Rhea D, et al. The impact of maternal obesity on the incidence of adverse pregnancy outcomes in high-risk term pregnancies. Am J Perinatol 2009;26:345-9.

4. Thorsdottir I, Torfadottir JE, Birgisdottir BE, et al. Weight gain in women of normal weight before pregnancy: complications in pregnancy or delivery and birth outcome. Obstet Gynecol 2002;99(5 Pt 1):799-806.

5. Kristensen J, Vestergaard M, Wisborg K, et al. Pre-pregnancy weight and the risk of stillbirth and neonatal death. BJOG 2005;112:403-8.

6. Robinson SM, Crozier SR, Harvey NC, et al. Modifiable early-life risk factors for childhood adiposity and overweight: an analysis of their combined impact and potential for prevention. Am J Clin Nutr 2015;101:368-75.

7. Houghton LC, Ester WA, Lumey LH, et al. Maternal weight gain in excess of pregnancy guidelines is related to daughters being overweight 40 years later. Am J Obstet Gynecol 2016;215:246.e1-8.

8. Hutcheon JA, Chapinal N, Bodnar LM, et al. The INTERGROWTH21st gestational weight gain standard and interpregnancy weight increase: a population-based study of successive pregnancies. Obesity 2017;25:1122-7.

9. Gilmore LA, Klempel-Donchenko M, Redman LM. Pregnancy as a window to future health: excessive gestational weight gain and obesity. Semin Perinatol 2015;39:296-303.

10. Leddy MA, Power ML, Schulkin J. The impact of maternal obesity on maternal and fetal health. Rev Obstet Gynecol 2008;1:170-8.

11. Melzer K, Schutz Y. Pre-pregnancy and pregnancy predictors of obesity. Int J Obes 2010;34(Suppl 2):S44-52.

12. Scott C, Andersen CT, Valdez N, et al. No global consensus: a cross-sectional survey of maternal weight policies. BMC Pregnancy Childbirth 2014;14:167.

13. Health Canada. Healthy weight gain during pregnancy. Ottawa, Canada: Government of Canada, 2014

14 Institute of Medicine. In: Rasmussen KM, Yaktine A, eds. Weight gain during pregnancy: reexamining the guidelines. Washington, DC: National Academies Press, 2009.

15. Institute of Medicine. Implementing guidelines on weight gain and pregnancy. Bethesda, MD: Institute of Medicine and National Research Council, 2013.

16. O'Connor DL, Blake J, Bell R, et al. Canadian consensus on female nutrition: adolescence, reproduction, menopause, and beyond. J Obstet Gynaecol Can 2016;38:508-54.

17. Australian Government. Healthy eating when you're pregnant or breastfeeding canberra, Australia: National Health and Medical Research Council; 2015. 2017 https://www.eatforhealth.gov.au/ eating-well/healthy-eating-throughout-all-life/healthy-eating-whenyou\%E2\%80\%99re-pregnant-or-breastfeeding

18. American College of Obstetricians and Gynecologists. Nutrition during pregnancy 2015. 2017 http://www.acog.org/Patients/ACOGPregnancy-Book

19. Swedish National Food Agency. Food for you who are pregnant. Uppsala, Sweden: Swedish National Food Agency, 2015.

20. Lutsiv O, Bracken K, Pullenayegum E, et al. Little congruence between health care provider and patient perceptions of counselling on gestational weight gain. J Obstet Gynaecol Can 2012;34:518-24.

21. Ferrari RM, Siega-Riz AM, Evenson KR, et al. Provider advice about weight loss and physical activity in the postpartum period. J Womens Health 2010;19:397-406.

22. Nikolopoulos H, Mayan M, Maclsaac J, et al. Women's perceptions of discussions about gestational weight gain with health care providers during pregnancy and postpartum: a qualitative study. BMC Pregnancy Childbirth 2017;17:97

23. Chang T, Llanes M, Gold KJ, et al. Perspectives about and approaches to weight gain in pregnancy: a qualitative study of physicians and nurse midwives. BMC Pregnancy Childbirth 2013;13:47

24. Duthie EA, Drew EM, Flynn KE. Patient-provider communication about gestational weight gain among nulliparous women: a qualitative study of the views of obstetricians and first-time pregnant women. BMC Pregnancy Childbirth 2013;13:231.

25. Herring SJ, Platek DN, Elliott P, et al. Addressing obesity in pregnancy: what do obstetric providers recommend? J Womens Health 2010;19:65-70.

26. Stotland NE, Gilbert P, Bogetz A, et al. Preventing excessive weight gain in pregnancy: how do prenatal care providers approach counseling? J Womens Health 2010;19:807-14.

27. Chalmers B, Dzakpasu S, Heaman M, et al. The Canadian maternity experiences survey: an overview of findings. J Obstet Gynaecol Can 2008;30:217-28.

28. Ferraro ZM, Boehm KS, Gaudet LM, et al. Counseling about gestational weight gain and healthy lifestyle during pregnancy: Canadian maternity care providers' self-evaluation. Int J Womens Health 2013;5:629-36.

29. McDonald SD, Pullenayegum E, Bracken K, et al. Comparison of midwifery, family medicine, and obstetric patients' understanding of weight gain during pregnancy: a minority of women report correct counselling. J Obstet Gynaecol Can 2012;34:129-35.

30. Zhang W, Creswell J. The use of "mixing" procedure of mixed methods in health services research. Med Care 2013;51:e51-7.

31. Creswell J, Klassen AC, Clark PV, et al. Best practices for mixed methods research in the health sciences. Bethesda, MD: Office of Behavioral and Social Sciences ResearchNational Institutes of Health, 2011.

32. Harris PA, Taylor R, Thielke R, et al. Research electronic data capture (REDCap)--a metadata-driven methodology and workflow process for providing translational research informatics support. J Biomed Inform 2009;42:377-81.

33. Health Canada. Prenatal nutrition guidelines for health professionals: gestational weight gain recommendations. Ottawa, ON: Health Canada, 2010.

34. Health Canada, Office of Nutrition Policy andPromotion. Eating well with canada's food guide. Ottawa, ON: Government of Canada, 2007.

35. Public Health Agency of Canada. Physical activity and pregnancy. Ottawa, ON: Public Health Agency of Canada, 2012.

36. Norman G. Likert scales, levels of measurement and the "laws" of statistics. Adv Health Sci Educ Theory Pract 2010;15:625-32.

37. Elo $\mathrm{S}$, Kyngäs $\mathrm{H}$. The qualitative content analysis process. $J$ Adv Nurs 2008;62:107-15.

38. Hsieh HF, Shannon SE. Three approaches to qualitative content analysis. Qual Health Res 2005;15:1277-88.

39. Patton M. Qualitative research and evaluation methods. 3rd edn. Thousand Oaks, CA: Sage, 2002.

40. Morse JM, Barrett M, Mayan M, et al. Verification strategies for establishing reliability and validity in qualitative research. Int J Qual Methods 2002;1:13-22.

41. Fetters MD, Curry LA, Creswell JW. Achieving integration in mixed methods designs-principles and practices. Health Serv Res 2013;48(6 Pt 2):2134-56.

42. Washington Cole KO, Gudzune KA, Bleich SN, et al. Influence of the 5A's counseling strategy on weight gain during pregnancy: an observational study. J Womens Health 2017;26:1123-30.

43. Peccei A, Blake-Lamb T, Rahilly D, et al. Intensive prenatal nutrition counseling in a community health setting: a randomized controlled trial. Obstet Gynecol 2017;130:423-32.

44. Mitchell LJ, Ball LE, Ross LJ, et al. Effectiveness of dietetic consultations in primary health care: a systematic review of randomized controlled trials. J Acad Nutr Diet 2017 (Epub ahead of print: 19 Aug 2017).

45. Heslehurst N, Newham J, Maniatopoulos G, et al. Implementation of pregnancy weight management and obesity guidelines: a metasynthesis of healthcare professionals' barriers and facilitators using the theoretical domains framework. Pregnancy Hypertens 2014:4:234-5.

46. Magriples U, Boynton MH, Kershaw TS, et al. The impact of group prenatal care on pregnancy and postpartum weight trajectories. Am J Obstet Gynecol 2015;213:688.e1-9. 